\title{
A Ilha da Ira: Conversas genealógicas Entrevista com João de Jesus Paes Loureiro
}

\author{
Dyellem Silva da COSTA* \\ Tânia SARMENTO-PANTOJA**
}

João de Jesus Paes Loureiro tornou-se merecidamente conhecido no cenário literário, especialmente como poeta, autor de coletâneas de poemas, como Tarefa (1964), Cantigas de amar, de amor e de paz (1966), As encantarias, Epístolas e Baladas (1968), Remo Mágico (1975), Enchente amazônica (1976), Porantim (1979), Deslendário (1981), A Loba (1990), Pentacantos (1984), Cantares amazônicos (1985), O Ser Aberto (1990), A poesia como encantaria da linguagem (1976), Iluminações/Iluminuras (1988), Artesão das Águas (1992), Altar em chamas e outros poemas (1989), Cinco palavras à Virgem de Nazaré (1989), Do Coração e suas amarras (2001), Fragmento (2003), Água da Fonte (2008), Para ler como quem anda nas ruas (1998). Além do romance Café Central (2011) o corpus de sua produção ficcional, embora menos conhecida e estudada, é constituída até momento pelas obras Pássaros da Terra (1999), Cutia de Ouro (1976), A Ilha da Ira (1976) e Procissão do Sayré (1977), todas narrativas que se destacam não apenas pelo valor artístico, como também pelo caráter documental em relação à cultura amazônica, caráter que se estende para o filtro sobre as formas de vida comunitárias.

No corpus, essencialmente dramatúrgico, ganha especial destaque a peça de teatro A Ilha da Ira, que é objeto da entrevista concedida pelo escritor, ora apresentada. Além da qualidade literária esta peça estabelece em sua escrita referências a episódios marcantes da história da Amazônia brasileira, constituídas com base no diálogo intertextual com a historiografia da Cabanagem e da Ditadura Civil e Militar de 1964. Destacamos também a presença de um conjunto de

\footnotetext{
* Graduada em Letras - Habilitação em Língua Portuguesa - UFPa (2014). Especialista em Educação em Direitos Humanos e Diversidade - UFPA (2016), Mestre em Educação, Área de Concentração: Identidades, Linguagens, Práticas e Representações - UFPA (2019). E-mail: dyellemcosta@ @otmail.com ** Doutora em Estudos Literários. Docente do Programa de Pós-Graduação em Letras e da Faculdade de Letras - Português (FALE), da Universidade Federal do Pará (UFPA). Bolsista Produtividade em Pesquisa. E-mail: nicama@ufpa.br
}

Revista Moara, n. 56, vol. 1, ago-dez 2020 ISSN:0104-0944 
referências lendárias e mitológicas, especialmente concentradas em mediar as formas de ser de uma política para o medo e para a morte. Sobre a centralidade da narrativa nesses temas, podemos dizer que em A Ilha da Ira há cenas de sequestros, tortura, assassinatos e desaparecimentos forçados, firmados como representações de práticas baseadas na logística de um poder governamental arbitrário e autoritário. É justamente no enlace dessas diretrizes que a temática do medo também vai buscar em suas representações a crítica às muitas formas de violação presentes na história da Amazônia brasileira. Essa organização de referências dispersas, porém, com condicionantes comuns, serve à composição de uma paisagem sombria e à constituição de uma das principais protagonistas da peça: a "Velha".

Com uma temática, portanto, amplamente relacionada ao seu tempo de produção, a década de 1970, Paes Loureiro constrói todo o universo da narrativa e, especialmente a protagonista da peça, com base em uma crítica ao poder soberano que emerge do Estado de Exceção. Mas, para além dessa possibilidade, como pode ser observado na entrevista, desde sua gênese de produção, a narrativa jamais perdeu de vista as imperiosas necessidades humanas, cujo espectro abastece a barbárie transmutada na repressão da liberdade, no assujeitamento e na desumanização em evidência no texto de A Ilha da Ira, bem como o caráter platónico sobre a natureza indômita do artista, mas, em termos sempre atuais, absolutamente necessária.

Ressaltamos ainda que com estas configurações, assim que veio a público, $A$ Ilha da Ira tornou-se alvo da censura, no âmbito do regime ditatorial instaurado em 1964. No acervo "Memórias Reveladas", sob a guarda do Arquivo Nacional, o Informe 99 E2/77, da 8 a . Região Militar do Ministério do Exército, datado de 16 de Dezembro de 1977, encaminhado ao então Reitor da Universidade Federal do Pará, instituição em que Paes Loureira exercia a docência, mostra bem a perseguição sofrida pelo escritor, em parte decorrente da encenação de A Ilha da Ira. O documento, de título "MOVIMENTO UNIVERSITÁRIO DA UFPa - ESCOLA DE TEATRO DA UFPa - PEÇA “A ILHA DA IRA”, é triplamente importante. Primeiro, porque esclarece definitivamente que a peça foi encenada pela primeira vez em 01 de dezembro de 1977. Segundo, mostra as engrenagens da repressão do Estado autoritário, na medida em que revela todos os nomes que compunham o elenco e a equipe artística. Segundo, informa o documento que tanto João de Jesus Paes 
Loureiro, quanto Cláudio Barradas, o diretor da peça, foram "fichados como comunistas", pela polícia a serviço da ditadura. Terceiro, conforme notícia publicada em um dos principais jornais da época, anexada ao referido documento, também revelam-se ligações entre os mecanismos de censura e repressão e certos segmentos da mídia jornalística, com base na circulação de informações inclinadas a criminalizar ou incitar à criminalização dos profissionais envolvidos na encenação da peça.

A entrevista foi concedida, inicialmente, para a pesquisa de mestrado intitulada "VIOLÊNCIA E MEDO EM A ILHA DA IRA, DE JOÃO DE JESUS PAES LOUREIRO" de autoria de Dyellem Silva da Costa e orientada por Tânia SarmentoPantoja. Foi realizado no dia 27 de agosto de 2018, na residência do escritor, em Belém do Pará.

Dyellem Silva e Tânia Sarmento-Pantoja: Primeiramente, qual seu nome completo, onde e quando nasceu?

João de Jesus Paes Loureiro: Meu nome é João de Jesus Paes Loureiro, sou filho de Abaetetuba, nascido em 1939.

DS/TSP: Qual é a chave para compreender o poder que a protagonista "Velha" exerce na narrativa de A Ilha da Ira?

PL: A razão da presença dessa figura na narrativa é a de atormentar a todos, pois ela é poderosa, autoritária, opressora. E essa imagem mítica da "Velha" simboliza uma reencarnação da Matintaperera, que, como um ser vingador, ela é uma alegoria do poder ditatorial, levando-se em consideração que essa peça é uma crítica à ditadura, uma oposição à tirania. É a arte que expressa seu sentimento, essa visão crítica do mundo, um cenário social, filosófico, através da ficção, de imagens que têm um caráter metafórico e simbólico. É a chave para se compreender essa relação de poder que ela exerce, de uma forma absolutamente arbitrária, sobre as pessoas. Nessa perspectiva, o artista fica visado e, apesar de não representar nenhum risco armado, ele caracteriza o risco da emoção, do pensamento, do sentimento, que, digamos assim, influencia muito 
as pessoas que têm contato com a obra de arte. É por isso que o artista é sempre muito perseguido nos regimes militares, porque há um temor da influência que ele possa causar no pensamento, na decisão, nas atitudes dos cidadãos. E isso não é de hoje, vem desde Platão, que idealizou o que era a República, em sua obra "A República”, em que ele elogia os artistas, simbolizados pelo poeta. Então ele elogia o poeta, diz que o mesmo tem que ser coroado com flores, homenagens e tudo mais, porque a República poderia influenciar a própria ordem, no sentido de criticar, no sentido de haver uma reação a essa República. Então, nesse núcleo de $A$ Ilha da Ira está concentrada a ideia temática da peça: ela vai ao sentido da condenação do artista, como forma de resistência à ditadura brasileira da época, mas que é, igualmente, uma oposição, uma crítica à ditadura de qualquer lugar. Na presente narrativa, ela está localizada apenas como exemplo de uma ditadura, mas que simboliza todas as outras ditaduras.

DS/TSP: Sobre a criação dos personagens na narrativa, qual foi sua inspiração?

PL: A criação dos personagens segue um pouco uma linha, em alguns casos, puramente dramática. Até mesmo para se ter um grupo de personagens masculinos e femininos, com o intuito de desenvolver uma ação dialogada. Porque todo teatro é isso: uma ação dialogada na presença de espectadores. E, assim, é uma ação dialogada que exige personagens, que vão lhe dando estrutura. Alguns são simbólicos, como, por exemplo, o Ulisseu, que é claramente uma alusão a Ulisses, aquele que luta, que vai contra Tróia, para tentar salvar a beleza de Helena de Tróia. Ele é um guerreiro que busca a liberdade. E, enfim, Patroni, outro personagem que é também uma alusão a Felipe Patroni, um exemplo de um personagem nosso, que lutou contra o autoritarismo (não era propriamente uma ditadura como a de agora, mas era contra o autoritarismo), contra o poder exercido por uma minoria, poder sem legitimação. Então são dois personagens, a meu ver, que têm uma significação, alusão histórica, demonstradora do caráter deles. No sentido da luta que eles têm, ao lado dessa figura da "Velha", que é também uma alegoria relativa ao imaginário da cultura local. Mas existem outros personagens também fictícios, como a Ana, por exemplo. 
DS/TSP: Como surgiu a ideia da peça como um todo?

PL: Essa peça, a localização dela, me surgiu quando, logo depois de 1964, eu tive que fazer uma viagem ao Maranhão. E nessa viagem eu fui para ajudar, representando um grande amigo nosso, que era de uma família de Abaetetuba, seu Teodoro Silva, cujos filhos eram meus amigos. Ele era dono de um barco desses da costeira, e comandante de um outro que viajava de Pernambuco para Belém trazendo cargas. E este naufragou na frente de uma localidade, no Maranhão, chamada de Vila dos Atins, que era uma vila de pescadores, com uma linda praia na frente. E, defronte dela, no mar, próximo da entrada, no rumo da foz do rio Amazonas, ali na Baía do Marajó, há uma formação de pedras submersas muito grandes, conhecida como Baixio dos Atins, nome que se dá popularmente para esse tipo de formação rochosa de pedras submersas no oceano, mas que fica quase que à flor das árvores. Esse lugar é muito perigoso até hoje. No passado, várias caravelas naufragaram ali, inclusive a caravela que vinha de Portugal, trazendo o grande poeta Gonçalves Dias, que vinha do Maranhão, porque ele estudava em Lisboa. Por isso, é um lugar muito temido ali. E eles [os tripulantes do barco de Teodoro Silva], por algum erro de cálculo, bateram lá e o barco afundou. Os tripulantes, porque não havia passageiros, conseguiram se salvar agarrados em tábuas, em barcos salva vidas. Ele também conseguiu, mas ficou muito machucado, não podendo retornar, nessa viagem, à São Luís, onde ele precisava ir porque haveria um inquérito marítimo que ele deveria responder, explicar o que teria acontecido na visão dele, e tudo o mais. Desse modo, ele pediu que eu fosse representá-lo, na ocasião. Contou-me toda a história e eu fui. Essa audiência era na Vila dos Atins, então, fui para lá. Ao chegar, fiquei hospedado na casa de um pescador, porque era uma vila de pescadores, localizada na praia, e percebi que era um lugarejo muito mítico, cheio de histórias fantásticas. E uma das coisas que me contaram, foi que a população até rezava para que houvesse naufrágios, mas não com mortes, porque quando havia mantimentos que ficavam boiando na água, os moradores traziam para a praia e dividiam entre eles. Era uma forma de ter fartura na ilha. Quer dizer, eu achei essa história tão dramática, e ao mesmo tempo tão trágica, que ficou na minha memória. E é por isso que eu situo esse acontecimento na peça, que começa com essa alusão trágica, com aquele coro no início da apresentação. No fundo, também, não é uma narração apenas do fato, é uma simbolização da carência que se 
vivia, da escassez que a população pobre enfrentava. E com isso eu quis inserir uma espécie de exemplo crítico. Claro que, na arte, não damos exemplos, mas, sim, mostramos para as pessoas entenderem certas condições. Então eu inseri essa ideia, e as coisas foram se juntando na minha cabeça, e outras imagens foram surgindo, lógico, então fui trabalhando a ideia. Eu estava na Faculdade de Letras, nesse tempo, e mandei o texto para o concurso do Serviço Nacional de Teatro. Ganhou em primeiro lugar, inclusive a peça do ano seguinte ganhou também, "Procissão do Sairé", que já tem outro aspecto, já que apresenta umas coisas que são atuais, como se fosse previsão do futuro: a questão da água, do roubo da mesma, que é o que está acontecendo hoje. É um pouco da estrutura da peça como um todo e a razão de certos personagens que são alegóricos, como Ulisseu e Patroni, para reforçar essas questões todas e fazer a ligação histórica da peça com a cultura grega, com a cultura amazônica e com o imaginário amazônico, que aparece na figura da Matinta. Eu não quis particularizar um herói. Você vê que todos os personagens são atirados no porão do navio, inclusive, isso também faz uma alusão histórica à Cabanagem, porque foi assim que aconteceu com os Cabanos. Na verdade, eu acabo identificando, no final, a reação contra aquele autoritarismo, com um castigo semelhante ao que havia ocorrido, historicamente, no caso da Cabanagem. A intenção, realmente, não foi particularizar um herói. Na verdade, os heróis são a população, o grupo de atores. Mas, ocorre que esse desaparecimento dele é simbólico, justamente para demonstrar que esse tipo de idealismo (porque é ele que lidera o grupo, ele que é o personagem rebelde da ilha) não morre, ele se transfere. Tanto que se transferiu do Ulisses, da cultura grega milenar, para Ulisseu, que é um personagem da peça Amazônica, e o fato dele não morrer é para mostrar que a luta continua. Dizendo, entre palavras, uma expressão mais comum, o idealismo continua. A simbologia da obra de arte não representa apenas aquilo que o autor idealizou, senão ela ficaria muito restrita. $\mathrm{Na}$ verdade, ela é mais extraída de todo e de tudo, do que do autor. E, às vezes, há leitor que possui interpretações mais ricas, mais bonitas do que o próprio autor dispõe, quando se trata de uma grande obra de arte. E é por isso que uma obra de arte atravessa o tempo. E o que garante sua perenidade é a interpretação e reinterpretação, ao longo do tempo do público leitor. 
DS/TSP: Você identifica problemas na encenação da peça, na época? Quais?

PL: Sim, existiram vários problemas na encenação. Ela foi exibida em Belém uma única vez. Nessa época, encenávamos na Escola Técnica Federal, com um grande diretor de teatro, que hoje é padre, Claudio Barradas. Professor e diretor de teatro, um dos melhores que já tivemos. Criativo, inovador e culto. Pois bem, ele resolve encenar, logo depois de 1964, a peça A Ilha da Ira. Isso em 1966, 1967, por aí (...), com alunos, inclusive, da Escola de Teatro da Universidade, que, na ocasião, tinha sido recémcriada, e se localizava entre a Quintino e a Gentil. Também havia alguns alunos dele da Escola Técnica, mas o espetáculo seria encenado pela Escola de Teatro. Pronta a encenação, um ou dois dias antes, haveria a visita da censura, que era na época da Ditadura. Um ou dois censores vinham e assistiam à encenação toda da peça. E iam dizendo o seguinte "corte isso, corte aquilo"; ou, então, "não está autorizada a ser encenada". E, assim, A Ilha da Ira não foi autorizada a ser encenada publicamente. E como era um expediente escrito e dirigido à Universidade, ficamos com o impasse. Então o Barradas teve uma ideia genial. Como a diretora técnica desse tempo, senhora Iolanda, tinha uma cabeça muita aberta e era uma ótima diretora, combinou-se de encenar na Escola Técnica como se fosse uma exibição interna para os alunos. Dessa maneira podia. Logo, programou-se três dias de exibição lá, e, de boca em boca, espalhou-se no meio artístico que quem quisesse poderia ir assistir ao espetáculo. Então, foram feitas três exibições. Teve muita gente, mas não se podia cobrar ingresso, nem nada, quem chegava entrava e assistia. E foi a primeira vez que ela foi encenada. Um dia eu tive a notícia, mas sem nenhum documento comprobatório, de que teria sido encenada no interior de São Paulo, anos depois, e também no Paraná. Estou falando de uma época em que o acesso a essa comunicação era muito precária. Hoje, não. Não tenho nenhum registro das produções da época. Uma vez encontrei um ex-aluno que, quando eu terminei uma palestra, veio falar comigo e disse que tinha participado dessa encenação de A Ilha da Ira.

DS/TSP: Qual a avaliação que você tem hoje de $A$ Ilha da Ira, em relação à época em que foi publicada? 
PL: Jornalisticamente, nenhuma. Os jornais não poderiam publicar uma matéria sobre a peça, porque para tanto teriam que discorrer sobre os problemas que ela alegorizava, questões sociais teriam que vir à tona. E ninguém publicaria. No caso dos expectadores, foi muito bem recebida, e as pessoas compreenderam toda a simbologia que ela expressa, e sempre questionavam o porquê de não poder ser interpretada mais vezes. Mas a maneira de exibir por meio desse modo estratégico foi o único jeito de poder garantir uma encenação.

DS/TSP: Na sua opinião, de que maneira a peça permanece atual?

PL: Ela permanece atual exatamente em seu sentido humano, e no sentido alegórico, porque ela trata de uma questão universal e atemporal, uma vez que sempre existiram e existem lugares com esse problema do autoritarismo extremo, ditaduras, repressão à população etc. $\mathrm{O}$ que talvez seja um pouco diferente da atualidade é que é um texto longo, com muitos intérpretes, o que dificulta uma encenação e exige atores experientes para representar os personagens. E, por ser uma peça muito literária e alegórica, não ficaria bem, digamos assim, se as falas fossem alteradas ou feitas adaptações na apresentação, como vemos muito na atualidade. Acho que quebraria o sentido do texto. Hoje, você sabe que o teatro leva muito em conta uma certa estrutura literária do texto, há muita improvisação e, de preferência, com poucos atores e cenários bem práticos, sem muita complicação. Por outro lado, a presença de cantigas na peça, uma herança da teoria de Bertold Brecht, que objetiva introduzir canções ao lado de situações que são críticas também da realidade, através de alegorias e da dimensão simbólica, corta um pouco a profundidade dramática. $\mathrm{O}$ som tem a ver com o movimento do enredo, mas se distancia um pouco da dimensão temática que uma peça de teatro normalmente tem. E, igualmente, a possibilidade da utilização de recursos audiovisuais, e tudo mais, ajuda nesse distanciamento, que é herança da teoria do distanciamento de Bertold Brecht. Eu convidei para colocar melodia na peça, nos poemas e nas letras, Waldemar Henrique, que é um compositor que tem uma herança musical extraordinária e é experiente em fazer música para teatro. Não é fácil fazer, é necessário ter uma técnica própria, uma estrutura peculiar. Ele fez com muito gosto. Não são muitas, no caso de A Ilha da Ira, mas são muito importantes no momento em que elas aparecem, e muito originais, quer 
dizer, não são músicas populares, são músicas para teatro. Já na peça Procissão do Sairé, tem um número bastante grande de canções que também são em parceria com Waldemar Henrique. Numa peça para o público infantil, Cutia de Ouro, também há um certo número de cantigas feitas com o Waldemar. E, a qual tem o número maior de músicas é a peça de teatro musicado Pássaro da Terra, que é inspirada na estrutura do Pássaro da Terra Junino. Esse é, realmente, um tipo de teatro musicado. Mas, a cantiga em A Ilha da Ira tem essa função de distanciamento, de criar uma...(...) de quebrar um pouco essa progressão dramática para fazer uma reflexão que a própria música, pela letra, estimula, comenta.

DS/TSP: Você pensa em produzir mais peças?

PL: No momento, não penso mais em fazer teatro. Só essas quatro peças. O que estou fazendo agora é um segundo romance, que penso publicar no ano que vem. Mas teatro, não. Eu tenho um texto que é para teatro de bonecos, mas nunca foi publicado ou encenado, e eu tenho tido muita precaução com ele, porque, depois de pronto, eu fiquei com receio de que ele ficasse muito mais voltado para adultos (risos), embora seja para o teatro infantil. Mas eu pretendo retomá-lo para ver se depois de ter ficado um pouco "de castigo", na gaveta, ele venha mais tranquilo para eu dar uma simplificada maior, para não o perder, porque acho que ele tem uma estrutura bem moderna. Mas, grande teatro eu não tenho intenção nenhuma de produzir. Romance, sim!

Revista Moara, n. 56, vol. 1, ago-dez 2020 ISSN:0104-0944 